(c) American Dairy Science Association, 2006.

\title{
Calving Difficulty and Stillbirths of Pure Holsteins versus Crossbreds of Holstein with Normande, Montbeliarde, and Scandinavian Red
}

\author{
B. J. Heins, ${ }^{1}$ L. B. Hansen, and A. J. Seykora \\ Department of Animal Science, University of Minnesota, St. Paul 55108
}

\section{ABSTRACT}

Pure Holstein cows and Normande/Holstein, Montbeliarde/Holstein, and Scandinavian Red/Holstein crossbred cows were compared for calving difficulty and stillbirth rates. Scandinavian Red was a combination of Norwegian Red and Swedish Red. All cows calved from June 2001 to August 2004 at 7 commercial dairies. Statistical models for analysis included effects of herdyear-season of calving and sex of calf in addition to breed of sire and breed group of dam. Male calves had significantly more calving difficulty and stillbirths than heifer calves. First-calf Holsteins bred to Holstein, Brown Swiss, Montbeliarde, and Scandinavian Red bulls were used to determine effects of breed of sire. Calves sired by Scandinavian Red bulls (5.5\%) and Brown Swiss bulls (12.5\%) had significantly less calving difficulty than calves sired by Holstein bulls (16.4\%) from Holstein first-calf heifers. Also, fewer stillbirths resulted from use of Scandinavian Red bulls (7.7\%) compared with use of Holstein bulls (15.1\%) for first-calf Holstein heifers. Scandinavian Red-sired calves (2.1\%) had significantly less calving difficulty than Holsteinsired calves (8.4\%) for multiparous Holstein dams. NonHolstein breeds of sire had significantly fewer stillbirths than Holstein sires when mated to multiparous Holstein dams. To determine the effects of breed of dam, 676 pure Holsteins, 262 Normande/Holstein, 370 Montbeliarde/Holstein, and 264 Scandinavian Red/Holstein crossbred virgin heifers that had been bred to Brown Swiss, Montbeliarde, and Scandinavian Red bulls were utilized. All groups of crossbred cows had significantly less calving difficulty at first calving than pure Holsteins (3.7 to $11.6 \%$ vs. $17.7 \%$ ). Furthermore, Montbeliarde/Holstein (6.2\%) and Scandinavian Red/ Holstein (5.1\%) crossbreds had significantly lower stillbirth rates at first calving than pure Holsteins (14.0\%). Key words: calving difficulty, crossbreeding, heterosis, stillbirth

Received October 28, 2005.

Accepted February 8, 2006.

${ }^{1}$ Corresponding author: hein0106@umn.edu

\section{INTRODUCTION}

Calving difficulty causes trauma for both cows and calves and can lead to increased rates of stillbirth, lower milk production, and reduced health of cows. Meyer et al. (2001b) reported that $23 \%$ of first-calving Holstein heifers need some level of assistance in the birthing process. Furthermore, stillbirth rates have increased in US Holsteins; and Meyer et al. (2001a) reported that the number of stillborn calves increased 3.7 percentage units among first-calf Holstein heifers over an 11-yr period. Dairy producers seek ways to reduce calving difficulty of cows and decrease stillbirths of calves in their herds; and some have turned to crossbreeding to potentially alleviate problems with these traits.

A survey of dairy producers conducted by Weigel and Barlass (2003) indicated that some respondents tried to reduce calving difficulty by mating their Holstein heifers to bulls of another breed. Producer scores for calving difficulty and stillbirth in the survey were best for crosses of Holstein and Jersey. Numerous studies have documented the impact of crossbreeding on calving difficulty and stillbirths, but they have been mostly limited to crossbreds of Holstein, Brown Swiss, Jersey, Ayrshire, and Guernsey (Donald, 1963; Hollon and Branton, 1975; Vesely et al., 1986; Touchberry, 1992).

From 1948 to 1962, stillbirths from 2,049 calvings in Great Britain were recorded by Donald (1963), and purebred calves of Holstein, Ayrshire, and Jersey breeds were compared with crossbred calves of each of the 3 breeds. At first calving, pure Holstein dams had 19.1\% stillborn calves vs. $4.7 \%$ for Ayrshire and $11.0 \%$ for Jerseys when bred to Holstein, Ayrshire, or Jersey bulls, respectively. Crossbred calves out of purebred dams at first calving had significantly lower stillbirth rates $(6.4 \%)$ than purebred calves $(14.7 \%)$.

In a study by Hollon and Branton (1975), Brown Swiss-sired crosses (16.0\%) had the highest calving difficulty rates when compared with pure Holsteins $(11.9 \%)$ and Holstein-sired crosses (6.0\%). Furthermore, pure Holsteins (12.8\%) had the highest incidence of stillbirths at first calving when compared with crossbred cows sired by either Holstein $(6.9 \%)$ or Brown Swiss (6.7\%) bulls. Touchberry (1992) reported results of a long-term crossbreeding trial with Guernseys and 
Holsteins and documented significantly fewer crossbred than purebred calves dead within $24 \mathrm{~h}$ after birth. Of 947 Guernsey and Holstein purebred births, 9.0\% had stillborn calves compared with $6.2 \%$ of 1,068 crossbred births.

Vesely et al. (1986) reported pure Holstein cows had significantly higher stillbirth rates than pure Ayrshire, Ayrshire/Holstein, and Holstein/Ayrshire crossbred cows. Pure Holstein calves (15.1\%) had higher stillbirth rates than calves from Ayrshire-sired calves of Holstein dams (10.7\%) and Holstein-sired calves of Ayrshire dams (7.0\%). Pure Holstein cows (14.5\%) had significantly more stillborn calves than Ayrshire/Holstein crossbred cows $(6.4 \%)$ at first calving.

In more recent studies, McClintock et al. (2004) reported pure Holstein cows had more calving difficulty than Jersey/Holstein crossbreds. Heins et al. (2003) reported that Jersey-sired calves were born with significantly less calving difficulty than Holstein-sired calves out of pure Holstein cows.

The objectives of this study were to determine the calving difficulty and stillbirth rates 1) in pure Holstein females bred to Holstein, Brown Swiss, Normande, Montbeliarde, or Scandinavian Red (SR) bulls; and 2) in pure Holstein cows vs. crossbred cows of Holstein with Normande, Montbeliarde, and SR.

\section{MATERIALS AND METHODS}

\section{Background}

The decline in fertility and survival of pure Holsteins led the managers of 7 large commercial dairies in California to mate Holstein heifers and cows with imported AI semen of the Normande and Montbeliarde breeds from France, as well as the Swedish Red breed and the Norwegian Red breed. The Swedish Red and Norwegian Red breeds share similar ancestry-mostly Ayrshire and Shorthorn-and exchange sires of sons; therefore, the breeds were collectively regarded as SR for this study.

All 7 dairies were enrolled in standard milk recording. They used AI for the majority of matings; however, some natural-service Holstein and Brown Swiss bulls were used for cows that were problem breeders. Sires for AI were selected amongst highest-ranking bulls with the Net Merit index for Holsteins and similar indices for the other breeds. Herd sizes range from approximately 500 to 1,500 cows. Production of cows in these dairies is provided in Heins et al. (2006).

\section{Data}

Calving difficulty and stillbirths were recorded for calvings from June 2001 to August 2004 on 7 large commercial dairies in central California. Calving difficulty was measured on a 1 to 5 scale, with 1 = quick, easy birth with no assistance; $2=$ over $2 \mathrm{~h}$ in labor, but no assistance; 3 = minimum assistance, but no calving difficulty; $4=$ used obstetrical chains; and $5=$ extremely difficult birth that required a mechanical puller. For analysis, scores of 1 to 3 were combined and represented no calving difficulty, whereas scores of 4 and 5 were combined and represented calving difficulty. Stillbirths were recorded in a binary manner as alive (1) or dead (0). A calf was considered stillborn if it died within $24 \mathrm{~h}$ of birth. Twin calves and calves resulting from abortions were omitted from the data. Birth weights of calves were not recorded by dairy producers and were not available.

Unadjusted means for first-calf heifers were $10.8 \%$ for calving difficulty and $10.9 \%$ for stillbirths. For multiparous cows, unadjusted means were $5.0 \%$ for calving difficulty and $5.2 \%$ for stillbirths.

\section{Breed of Sire}

Pure Holstein dams were bred to Holstein, Brown Swiss, Normande, Montbeliarde, and SR bulls and resulting calvings were used for the analysis of breed of sire. Pure Holstein dams were separated into first-calf cows and second-calf to fifth-calf cows. Normande bulls were not included in the analysis of first calving because only 24 calvings were recorded. Data for the analysis of breed of sire were collected for calvings for the entire period from June 2001 to August 2004.

Herd-year-seasons were based on 4-mo seasons of calving and derived from climatic conditions in California. June, July, August, and September are especially hot months; October, November, December, and January are rainy months; and February, March, April, and May are cool and dry months. With data spanning June 2001 to August 2004, each herd had the potential of contributing 7 year-seasons of calving for first calving and 10 year-seasons for second to fifth calving.

Each herd-year-season was required to have calvings with more than a single breed of sire. Following this edit, 45 herd-year-seasons for first calving and 55 herdyear-seasons for second to fifth calving remained. Furthermore, 1,593 first-calf and 4,041 second-calf to fifthcalf pure Holstein dams remained in the data file. The 4,041 multiparous Holsteins were composed of 1,619 second-, 1,279 third-, 742 fourth-, and 401 fifth-calving cows.

Dependent variables in the model for statistical analysis were calving difficulty and stillbirths. Independent variables for first calving were the fixed effects of herdyear-season, sex of calf, and breed of sire. For the analysis of second to fifth calving, lactation number was 
Table 1. Number of first-calf and second-calf cows by breed of service sire for breed groups of dam

\begin{tabular}{|c|c|c|c|c|c|c|c|c|}
\hline \multirow[b]{2}{*}{ Breed group of dam } & \multicolumn{4}{|c|}{ First-calf breed of sire } & \multicolumn{4}{|c|}{ Second-calf breed of sire } \\
\hline & $\mathrm{n}$ & $\begin{array}{l}\text { Brown } \\
\text { Swiss }\end{array}$ & Montbeliarde & $\begin{array}{l}\text { Scandinavian } \\
\text { Red }\end{array}$ & $\mathrm{n}$ & $\begin{array}{l}\text { Brown } \\
\text { Swiss }\end{array}$ & Montbeliarde & $\begin{array}{l}\text { Scandinavian } \\
\text { Red }\end{array}$ \\
\hline Normande/Holstein & 262 & 52 & 10 & 200 & 190 & 35 & 39 & 116 \\
\hline Montbeliarde/Holstein & 370 & 273 & 6 & 91 & 75 & 56 & 4 & 15 \\
\hline Scandinavian Red/Holstein & 264 & 32 & 193 & 39 & 69 & 8 & 54 & 7 \\
\hline Total & 1,572 & 537 & 239 & 796 & 641 & 150 & 278 & 213 \\
\hline
\end{tabular}

added as a fixed effect and cow was added as a random variable in the model. For first calving, the GLM procedure of SAS (SAS Institute, 2004) was used to obtain solutions. For second to fifth calving, the mixed model procedure of SAS (SAS Institute, 2004) was used to obtain solutions. Logistic regression (SAS Institute, 2004) was used to determine statistical significance because both calving difficulty and stillbirths were binary traits. Significance of differences between fixed effects are reported using contrasts from the logistic regression analysis.

\section{Breed of Dam}

For breed of dam, pure Holstein dams and crossbred dams of Holstein with Normande, Montbeliarde and SR were bred to Brown Swiss, Montbeliarde, and SR bulls. Breeds of sire were limited to these 3 breeds because number of births by sires of other breeds were small and were not well distributed across breed groups of dams. Therefore, all births analyzed for effect of breed of dam were for crossbred calves. Data for the analysis of breed of dam were collected for calvings from June 2002 to August 2004 and included only first and second calvings.

Herd-year-season of calving was based on the same 4-mo climatic conditions used for breed of sire, and herd-year-seasons were required to have calvings with more than a single breed group of dam. Following this edit, 51 herd-year-seasons for first calving and 26 herdyear-seasons for second calving remained for the breed of dam analysis. Also, 1,572 first calvings of heifers remained and included 676 pure Holstein dams, as well as 262 Normande/Holstein, 370 Montbeliarde/Holstein, and $264 \mathrm{SR} /$ Holstein crossbred dams (Table 1). For second calving, 307 pure Holstein dams were compared with 190 Normande/Holstein, 75 Montbeliarde/Holstein, and 69 SR/Holstein crossbred dams (Table 1). The distribution of first-calf heifers by herd and breed group is in Table 2 . The 7 herds were variable in number of cows and in extent of use of crossbreeding.

Dependent variables in the model for the statistical analysis of breed of dam were calving difficulty and stillbirths. Independent variables were the fixed effects of herd-yr-season, sex of calf, breed of service sire, and breed group of dam. The GLM procedure of SAS (SAS Institute, 2004) was used to obtain solutions. Logistic regression (SAS Institute, 2004) was used to assess the statistical significance for the binary traits of calving difficulty and stillbirths.

\section{RESULTS AND DISCUSSION}

\section{Effect of Breed of Sire}

Herd-year-season of calving was significant $(P<0.01)$ for calving difficulty of first-calf Holsteins and for both calving difficulty and stillbirths of second-calf to fifthcalf Holstein dams. Herd-year-season was not significant for stillbirths of first-calf Holsteins. For secondcalf to fifth-calf pure Holsteins, lactation number was not significant for calving difficulty or stillbirths.

Sex of calf explained significant variation $(P<0.01)$ for calving difficulty and stillbirths of first-calf Holstein dams as well as second-calf to fifth-calf Holstein dams. Across breeds of sire for first-calf pure Holstein cows, least squares means for calving difficulty were $15.9 \%$ for bull calves and $7.0 \%$ for heifer calves, and least squares means for stillbirth rates were $18.6 \%$ for bull calves and $5.0 \%$ for heifer calves. Cows calving for the second to fifth time had less calving difficulty and fewer stillbirths than first-calf heifers, but bull calves again were more of a problem $(P<0.01)$ than heifer calves

Table 2. Number of births by herd and breed group for first-calf dams

\begin{tabular}{lllll}
\hline & & \multicolumn{3}{c}{ Crossbreds } \\
\cline { 3 - 5 } Herd & Pure & Normande/ & Montbeliarde/ & Scandinavian \\
& Holstein & Holstein & Holstein & Red/Holstein \\
\hline 1 & 50 & 32 & 96 & 52 \\
2 & 121 & 113 & 124 & 67 \\
3 & 94 & 35 & 64 & 58 \\
4 & 58 & 28 & 76 & 31 \\
5 & 302 & 19 & 9 & 51 \\
6 & 39 & 11 & 0 & 2 \\
7 & 12 & 24 & 1 & 3 \\
\hline
\end{tabular}


Table 3. Number of observations, least squares means, and significance from the logistical regression statistical test ${ }^{1}$ for calving difficulty and stillbirths by breed of sire

\begin{tabular}{|c|c|c|c|c|c|c|}
\hline \multirow[b]{2}{*}{ Breed of sire } & \multicolumn{3}{|c|}{ First-calf Holstein dams } & \multicolumn{3}{|c|}{ Second- to fifth-calf Holstein dams } \\
\hline & $\mathrm{n}$ & $\begin{array}{l}\text { Calving } \\
\text { difficulty } \\
(\%)\end{array}$ & $\begin{array}{l}\text { Stillbirths } \\
(\%)\end{array}$ & $\mathrm{n}$ & $\begin{array}{l}\text { Calving } \\
\text { difficulty } \\
(\%)\end{array}$ & $\begin{array}{l}\text { Stillbirths } \\
(\%)\end{array}$ \\
\hline Holstein & 371 & 16.4 & 15.1 & 303 & 8.4 & 12.7 \\
\hline Brown Swiss & 209 & $12.5^{* *}$ & 11.6 & 524 & 4.9 & $5.6^{* * *}$ \\
\hline Normande & 0 & - & - & 326 & 8.7 & $7.3^{*}$ \\
\hline Montbeliarde & 158 & 11.6 & 12.7 & 2,373 & 5.4 & $5.0 * *$ \\
\hline Scandinavian Red & 855 & $5.5^{* *}$ & $7.7^{* *}$ & 515 & $2.1^{* *}$ & $4.7 * *$ \\
\hline
\end{tabular}

${ }^{1}$ Paired contrasts were used to compare breeds of sire with Holstein sires.

${ }^{*} P<0.05$ for contrast of difference from pure Holstein; ${ }^{*} P<0.01$ for contrast of difference from pure Holstein.

for calving difficulty (7.5 vs. $4.3 \%)$ and stillbirths $(8.5$ vs. $5.6 \%)$.

McClintock et al. (2004) and Meyer et al. (2001a) reported that bull calves were born with more calving difficulty and higher stillbirth rates for first-calf heifers and multiparous cows; however, across all generations of a crossbreeding study, Touchberry (1992) reported more heifer calves were stillborn than bull calves. Adamec et al. (2006) and Vesely et al. (1986) reported a reduction in calving difficulty and stillbirths from bull calves in multiparous dams compared with first-calf heifers; however, the differences were not as large as this study. Larger bull calves than heifer calves and smaller pelvic dimensions in first-calf heifers compared with multiparous cows are likely factors contributing to an increase in calving difficulty and stillbirths, as suggested by Steinbock et al. (2003) and Meijering (1984).

Number of observations and least squares means for calving difficulty and stillbirths by breed of sire for firstcalf and second- to fifth-calf pure Holstein dams are in Table 3. Also, significance levels from paired contrasts from the logistic regression statistical test for effect of breed of sire on calving difficulty and stillbirths are in Table 3. Calves sired by Holstein bulls had significantly more $(P<0.01)$ calving difficulty $(16.4$ vs. $5.5 \%)$ and stillbirths (15.1 vs. $7.7 \%$ ) than calves sired by SR bulls from first-calf Holstein heifers. Holstein sires also had significantly more $(P<0.01)$ calving difficulty $(16.4 \mathrm{vs.}$ $12.5 \%$ ) than Brown Swiss sires. Montbeliarde sires did not differ significantly from Holstein sires for calving difficulty or stillbirths of first-calf Holstein dams. These results are similar to Cole et al. (2005), who indicated that Brown Swiss-sired calves had slightly less calving difficulty than Holstein-sired calves. Also, McClintock et al. (2004) documented that Holstein-sired calves from Holstein dams had more calving difficulty than Jerseysired calves from Holstein dams. Furthermore, Vesely et al. (1986) indicated than pure Holstein calves had higher stillbirth rates than crossbred calves. When surveyed, dairy producers stated that mating pure Holstein cows to Jersey or Brown Swiss sires reduced calving difficulty and stillbirths (Weigel and Barlass, 2003).

For dams calving a second to fifth time, calves sired by SR sires $(2.1 \%)$ had significantly less $(P<0.01)$ calving difficulty than Holstein sires (8.4\%). Calves by Holstein sires $(12.7 \%)$ also had significantly $(P<0.01)$ more stillbirths than calves by Brown Swiss sires (5.6\%), Montbeliarde sires $(5.0 \%)$, and SR sires $(4.7 \%)$. Calves sired by Holstein bulls were more likely to be stillborn than calves sired by Normande bulls $(7.3 \% ; P<0.05)$. In agreement with this study, Adamec et al. (2006) and Meyer et al. (2001a) found calving difficulty rates ranging from 6 to $11 \%$ for multiparous Holstein dams, but both studies found lower stillbirth rates (5 to 7\%) than this study for multiparous Holstein dams. However, both studies had over 100,000 records from 5,000 herds, whereas this study had cows from only 7 herds.

For the breed of sire analysis, all dams were pure Holsteins; therefore, calves sired by Holstein bulls were purebreds, whereas calves sired by bulls from other breeds were crossbreds. Crossbred calves should have more vitality from heterosis, which could result in less calving difficulty and fewer stillbirths. On the other hand, inbreeding could result in higher stillbirth rates for pure Holstein calves, due to undisclosed genetic recessives in the breed as suggested by Adamec et al. (2006). For example, complex vertebral malformation is a genetic recessive that results in fetal death (Hansen et al., 2004).

\section{Effect of Breed of Dam}

For breed group of dam, herd-year-season of first calving was significant $(P<0.05)$ for calving difficulty, but not significant for stillbirths. Effects of breed groups of dam, breed of sire, and sex of calf were significant $(P$ $<0.01$ ) for both calving difficulty and stillbirths at first 
Table 4. Number of observations, least squares means, and significance from the logistical regression statistical test ${ }^{1}$ for calving difficulty and stillbirths by breed group of dam ${ }^{2}$

\begin{tabular}{|c|c|c|c|c|c|c|}
\hline \multirow[b]{2}{*}{ Breed group of dam } & \multicolumn{3}{|c|}{ First calf } & \multicolumn{3}{|c|}{ Second calf } \\
\hline & $\mathrm{n}$ & $\begin{array}{l}\text { Calving } \\
\text { difficulty } \\
(\%)\end{array}$ & $\begin{array}{l}\text { Stillbirths } \\
(\%)\end{array}$ & $\mathrm{n}$ & $\begin{array}{l}\text { Calving } \\
\text { difficulty } \\
(\%)\end{array}$ & $\begin{array}{l}\text { Stillbirths } \\
(\%)\end{array}$ \\
\hline Pure Holstein & 676 & 17.7 & 14.0 & 307 & 3.1 & 3.7 \\
\hline Normande/Holstein & 262 & $11.6^{*}$ & 9.9 & 190 & 3.3 & 4.7 \\
\hline Montbeliarde/Holstein & 370 & $7.2^{* *}$ & $6.2^{* *}$ & 75 & 0.2 & 5.9 \\
\hline Scandinavian Red/Holstein & 264 & $3.7 * *$ & $5.1 * *$ & 69 & 1.9 & 2.3 \\
\hline
\end{tabular}

${ }^{1}$ Paired contrasts were used to compare breed groups of dam with pure Holstein dams.

${ }^{2}$ Breeds of sire were Brown Swiss, Montbeliarde, and Scandinavian Red.

$* P<0.05$ for contrast of difference from pure Holstein; $* * P<0.01$ for contrast of difference from pure Holstein.

calving of cows. Across breed groups of dam, calving difficulty and stillbirth rates were significantly $(P<$ 0.01) higher in bull calves than heifer calves for firstcalf heifers. Calving difficulty rates were $14.7 \%$ for bull calves and $5.3 \%$ for heifer calves, and stillbirth rates were $15.4 \%$ for bull calves and $2.2 \%$ for heifer calves. Once again, these results for sex of calf are similar to those of Adamec et al. (2006), McClintock et al. (2004), Meyer et al. (2001a), and Touchberry (1992). For second-calf dams, only breed of sire was significant $(P<$ $0.05)$ for stillbirths. No other effects were significant for stillbirths, and no effects were significant for calving difficulty for second-calf dams.

Number of observations and least squares means for breed groups of dam for calving difficulty and stillbirths for 1,572 first-calf heifers and 641 second-calf cows are in Table 4. Furthermore, paired contrasts from the logistic regression significance test for breed groups of dam for first-calf heifers and second-calf cows are in Table 4. Pure Holsteins (17.7\%) had significantly $(P<$ 0.01) more calving difficulty than Montbeliarde/Holstein $(7.2 \%)$ and SR/Holstein (3.7\%) crossbreds at first calving, and pure Holsteins had significantly $(P<0.05)$ more calving difficulty than Normande/Holstein crossbreds (11.6\%). Stillbirth rates tended to follow calving difficulty rates for breed groups of dam at first calving, and pure Holstein heifers (14.0\%) had significantly $(P<$ $0.01)$ higher stillbirth rates than Montbeliarde/Holstein (6.2\%) and SR/Holstein (5.1\%) crossbred heifers. Pure Holstein heifers also tended to have higher stillbirth rates than Normande/Holstein crossbred heifers (9.9\%). The results for stillbirths agree with the results of Hollon and Branton (1975) and Vesely et al. (1986), who reported pure Holstein cows at first calving had higher stillbirth rates than crossbred cows. McClintock et al. (2004) reported pure Holstein cows had more calving difficulty than Jersey/Holstein crossbred cows.

The stillbirth rates of the pure Holstein heifers in this study are higher than those of Meyer et al. (2001a), who reported a stillbirth rate of $13.2 \%$ in 1996 . However, Meyer et al. (2001a) found an increase in stillbirth rate of $3.7 \%$ over an 11-yr period; therefore, stillbirth rates of first-calf pure Holsteins might have continued to increase in the breed since 1996 up to the $17.7 \%$ stillbirth rate reported in this study.

Dematawewa and Berger (1997) indicated calving difficulty in Holsteins is associated with reduced milk production, longer days open, and lower survival. Dairy producers report less calving difficulty and fewer stillbirths when Holstein cows are crossed with Jersey and Brown Swiss bulls (Weigel and Barlass, 2003). Crossbreeding might be effective in reducing calving difficulty and stillbirths, thereby reducing costs associated with difficult births, including lower milk production and longer days open.

For cows that calved a second time, calving difficulty and stillbirth rates were lower than those for first-calf heifers. These results agree with Meyer et al. (2001b) and indicate that most calving difficulty and stillbirths occur for first-calf heifers. Breed groups of dam were not significantly different from one another for calving difficulty or stillbirths.

\section{CONCLUSIONS}

As expected, bull calves had significantly more calving difficulty and higher stillbirth rates than heifer calves in all cases. Holstein-sired calves were born with significantly more calving difficulty and with a greater frequency of stillbirths than calves sired by SR sires out of both first-calf and multiparous pure Holstein dams. Furthermore, Brown Swiss-sired calves were born with less difficulty than Holstein-sired calves at first calving from pure Holstein dams. Calves sired by breeds of sire other than Holstein had significantly lower stillbirth rates than calves sired by Holstein bulls from multiparous pure Holstein cows. 
First-calf Normande/Holstein, Montbeliarde/Holstein, and SR/Holstein crossbred heifers had significantly less calving difficulty than first-calf pure Holsteins. Also, Montbeliarde/Holstein and SR/Holstein crossbred heifers had significantly fewer stillbirths than first-calf pure Holsteins.

The results of this study suggest that dairy producers can lessen calving difficulty and reduce stillbirths by crossing Holstein cows with bulls of other dairy breeds, and the resulting crossbred females will also tend to have lessened calving difficulty and reduced stillbirths at first calving. Additional research should aid in determining if the economics of dairy production justify the use of crossbreeding as a tool to reduce calving difficulty and stillbirths.

\section{ACKNOWLEDGMENTS}

The authors are especially grateful to the managers of the 7 California dairies, who willingly provided data from their cows. Without their cooperation, this study would not have been possible.

\section{REFERENCES}

Adamec, V., B. G. Cassell, E. P. Smith, and R. E. Pearson. 2006. Effects of inbreeding in the dam on dystocia and stillbirths in US Holsteins. J. Dairy Sci. 89:307-314.

Cole, J. B., R. C. Goodling, Jr., G. R. Wiggans, and P. M. VanRaden. 2005. Genetic evaluation of calving ease for Brown Swiss and Jersey bulls from purebred and crossbred calvings. J. Dairy Sci. 88:1529-1539.

Dematawewa, C. M., and P. J. Berger. 1997. Effect of dystocia on yield, fertility, and cow losses and an economic evaluation of dystocia scores for Holsteins. J. Dairy Sci. 80:754-761.
Donald, H. P. 1963. Perinatal deaths among calves in a crossbred dairy herd. Anim. Prod. 5:87-95.

Hansen, M., I. Misztal, M. S. Lund, J. Pederson, and L. G. Christensen. 2004. Undesired phenotypic and genetic trend for stillbirth in Danish Holsteins. J. Dairy Sci. 87:1477-1486.

Heins, B. J., L. B. Hansen, and A. J. Seykora. 2006. Production of pure Holsteins versus crossbreds of Holstein with Normande, Montbeliarde, and Scandinavian Red. J. Dairy Sci. 89:2799-2804.

Heins, B. J., A. J. Seykora, L. B. Hansen, J. G. Linn, and W. P. Hansen. 2003. Effect of mating Holstein females to Holstein versus Jersey AI sires on fertility, dystocia, calf weight, and retained placenta. J. Dairy Sci. 86(Suppl. 1):130. (Abstr.)

Hollon, B. F., and C. Branton. 1975. Performance of Holstein and crossbred dairy cattle in Louisiana. III. Health and viability. J. Dairy Sci. 58:93-101.

McClintock, S., B. Kevin, M. Wells, and G. Michael. 2004. Calving difficulty in Holsteins and Jerseys and their crossbreds. J. Dairy Sci. 87(Suppl 1):284. (Abstr.)

Meijering, A. 1984. Dystocia and stillbirth in cattle - A review of causes, relations, and implications. Livest. Prod. Sci. 11:143-177.

Meyer, C. L., P. J. Berger, K. J. Koehler, J. R. Thompson, and C. G. Sattler. 2001a. Phenotypic trends in incidence of stillbirth for Holsteins in the United States. J. Dairy Sci. 84:515-523.

Meyer, C. L., P. J. Berger, J. R. Thompson, and C. G. Sattler. 2001b. Genetic evaluation of Holstein sires and maternal grandsires in the United States for perinatal survival. J. Dairy Sci. 84:12461254.

SAS Institute. 2004. SAS/STAT Software, Release 9.1.3. SAS Institute, Inc., Cary, NC.

Steinbock, L., A. Näsholm, B. Berglund, K. Johansson, and J. Phillipsson. 2003. Genetics effects on stillbirth and calving difficulty in Swedish Holsteins at first and second calving. J. Dairy Sci. 86:2228-2235.

Touchberry, R. W. 1992. Crossbreeding effects in dairy cattle: the Illinois experiment, 1949 to 1969. J. Dairy Sci. 75:640-667.

Vesely, J. A., A. J. McAllister, A. J. Lee, T. R. Batra, C. Y. Lin, G. L. Roy, J. M. Wauthy, and K. A. Winter. 1986. Reproductive performance of crossbred and purebred dairy cows. J. Dairy Sci. 69:518-526.

Weigel, K. A., and K. A. Barlass. 2003. Results of a producer survey regarding crossbreeding on US dairy farms. J. Dairy Sci. $86: 4148-4154$. 